\title{
Dutch Translation of the Perth Alexithymia Questionnaire
}

\section{Nederlandstalige vertaling van de Perth Alexithymia Questionnaire}

\author{
Marta Walentynowicz \\ UCLouvain, Belgium \\ marta.walentynowicz@uclouvain.be \\ Elke Vlemincx \\ VU University Amsterdam, The Netherlands \\ e.vlemincx@vu.nl \\ David A. Preece \\ Curtin University \& The University of Western Australia, Australia \\ david.preece@curtin.edu.au \\ Olivier Luminet \\ UCLouvain, Belgium \\ olivier.luminet@uclouvain.be
}

\section{Vertaalproces}

Deze Nederlandstalige vertaling van de Perth Alexithymia Questionnaire (PAQ) is vertaald vanuit de oorspronkelijke Engelse versie. Een eerste vertaling van het Engels naar het Nederlands werd uitgevoerd en verfijnd door het auteursteam. Deze Nederlandstalige items werden vervolgens terugvertaald naar het Engels door een door NAATI erkende vertaler. Op basis van deze hervertaling zijn door het auteursteam kleine verfijningen aangebracht in enkele Nederlandstalige items, wat heeft geleid tot de definitieve Nederlandstalige versie van de PAQ die in dit document wordt gepresenteerd.

Ons team voert momenteel een psychometrische studie uit op deze Nederlandstalige PAQ om de validiteit en betrouwbaarheid te onderzoeken.

This Dutch translation of the Perth Alexithymia Questionnaire (PAQ) was translated from the original English version. An initial translation from English to Dutch was conducted and refined by the authorship team. These Dutch items were then back-translated into English by a NAATI approved translator. Minor refinements to some of the Dutch items were made by the authorship team on the basis of this backtranslation, resulting in the final Dutch version of the PAQ presented in this document.

Our team is currently conducting a psychometric study on this Dutch PAQ to examine its validity and reliability. 
Deze vragenlijst bevraagt hoe jij jouw emoties waarneemt en ervaart. Gelieve voor de volgende uitspraken aan te geven in welke mate je het eens of oneens bent dat de uitspraak van toepassing is op jou. Omcirkel één antwoord voor iedere uitspraak.

In sommige vragen worden slechte gevoelens of onaangename emoties vermeld, dit betekent emoties zoals verdriet, woede of angst. In sommige vragen worden goede gevoelens of aangename emoties vermeld, dit betekent emoties zoals blijdschap, amusement of opwinding.

\begin{tabular}{ccccccc}
$\begin{array}{c}\text { Helemaal } \\
\text { oneens }\end{array}$ & - & & $\begin{array}{c}\text { Noch } \\
\text { eens, } \\
\text { noch } \\
\text { oneens }\end{array}$ & $-\ldots$ & $-\cdots$ & $\begin{array}{c}\text { Helemaal } \\
\text { mee } \\
\text { eens }\end{array}$ \\
\hline
\end{tabular}

Wanneer ik me slecht voel (een

onaangename emotie ervaar), kan ik de

juiste woorden niet vinden om die

1

234

5

6

7

gevoelens te beschrijven.

Wanneer ik me slecht voel, weet ik niet of ik

verdrietig, boos of angstig ben.

$\begin{array}{lllllll}1 & 2 & 3 & 4 & 5 & 6 & 7\end{array}$

$3 \quad$ Ik heb de neiging te negeren hoe ik me voel.

1

23

4

5

6

7

Wanneer ik me goed voel (een aangename emotie ervaar), kan ik de juiste woorden niet vinden om die gevoelens te 1

12

3

4

5

6

7

beschrijven.

Wanneer ik me goed voel, weet ik niet of ik me blij, opgewonden of geamuseerd voel.

1

2

3

4

5

6

Ik laat mijn gevoelens liever in de

6 achtergrond gebeuren dan op hen te focussen.

Wanneer ik me slecht voel, kan ik niet

7 diepgaand of in detail praten over die gevoelens.

1

23

4

5

6

7

Wanneer ik me slecht voel, kan ik die gevoelens niet begrijpen.

$\begin{array}{lllllll}1 & 2 & 3 & 4 & 5 & 6 & 7\end{array}$

$9 \quad$ Ik let niet op mijn emoties.

1

2

1

2

3

4

5

6

7 gevoelens.

11 Wanneer ik me goed voel, kan ik die gevoelens niet begrijpen.

1

$\begin{array}{lllllll}1 & 2 & 3 & 4 & 5 & 6 & 7\end{array}$




\begin{tabular}{|c|c|c|c|c|c|c|c|c|}
\hline & & $\begin{array}{l}\text { Helemaal } \\
\text { oneens }\end{array}$ & ---- & ---- & $\begin{array}{l}\text { Noch } \\
\text { eens, } \\
\text { noch } \\
\text { oneens }\end{array}$ & --- & ---- & $\begin{array}{l}\text { Helemaal } \\
\text { mee } \\
\text { eens }\end{array}$ \\
\hline 13 & $\begin{array}{l}\text { Wanneer iets slechts gebeurt, is het moeilijk } \\
\text { voor mij om onder woorden te brengen hoe } \\
\text { ik me voel. }\end{array}$ & 1 & 2 & 3 & 4 & 5 & 6 & 7 \\
\hline 14 & $\begin{array}{l}\text { Wanneer ik me slecht voel, raak ik in de war } \\
\text { over welke emotie het is. }\end{array}$ & 1 & 2 & 3 & 4 & 5 & 6 & 7 \\
\hline 15 & $\begin{array}{l}\text { Ik focus me liever op dingen die ik } \\
\text { daadwerkelijk kan zien en aanraken, dan op } \\
\text { mijn emoties. }\end{array}$ & 1 & 2 & 3 & 4 & 5 & 6 & 7 \\
\hline 16 & $\begin{array}{l}\text { Wanneer iets goeds gebeurt, is het moeilijk } \\
\text { voor mij om onder woorden te brengen hoe } \\
\text { ik me voel. }\end{array}$ & 1 & 2 & 3 & 4 & 5 & 6 & 7 \\
\hline 17 & $\begin{array}{l}\text { Wanneer ik me goed voel, raak ik in de war } \\
\text { over welke emotie het is. }\end{array}$ & 1 & 2 & 3 & 4 & 5 & 6 & 7 \\
\hline 18 & $\begin{array}{l}\text { Ik probeer niet 'in contact' te zijn met mijn } \\
\text { emoties. }\end{array}$ & 1 & 2 & 3 & 4 & 5 & 6 & 7 \\
\hline 19 & $\begin{array}{l}\text { Als ik probeer te beschrijven hoe ik me voel } \\
\text { wanneer ik me slecht voel, weet ik niet wat } \\
\text { te zeggen. }\end{array}$ & 1 & 2 & 3 & 4 & 5 & 6 & 7 \\
\hline 20 & $\begin{array}{l}\text { Wanneer ik me slecht voel, ben ik in de war } \\
\text { door die gevoelens. }\end{array}$ & 1 & 2 & 3 & 4 & 5 & 6 & 7 \\
\hline 21 & $\begin{array}{l}\text { Het is niet belangrijk voor mij om te weten } \\
\text { wat ik voel. }\end{array}$ & 1 & 2 & 3 & 4 & 5 & 6 & 7 \\
\hline 22 & $\begin{array}{l}\text { Als ik probeer te beschrijven hoe ik me voel } \\
\text { wanneer ik me goed voel, weet ik niet wat } \\
\text { te zeggen. }\end{array}$ & 1 & 2 & 3 & 4 & 5 & 6 & 7 \\
\hline 23 & $\begin{array}{l}\text { Wanneer ik me goed voel, ben ik in de war } \\
\text { door die gevoelens. }\end{array}$ & 1 & 2 & 3 & 4 & 5 & 6 & 7 \\
\hline 24 & $\begin{array}{l}\text { Het is vreemd voor mij om na te denken } \\
\text { over mijn emoties. }\end{array}$ & 1 & 2 & 3 & 4 & 5 & 6 & 7 \\
\hline
\end{tabular}




\section{Perth Alexithymia Questionnaire (PAQ) - Instructies voor het scoren}

Alexithymie is een multidimensioneel construct dat uit drie componenten bestaat: moeite met het identificeren van de eigen gevoelens (DIF); moeite met het beschrijven van gevoelens (DDF); en een extern georiënteerde denkstijl (EOT) waarbij men de neiging heeft de aandacht niet op de eigen emoties te richten. Met andere woorden, mensen met hoge niveaus van alexithymie hebben moeite om hun aandacht te richten op hun emotionele toestand (EOT), en moeite om nauwkeurig in te schatten wat die toestand is (DIF, DDF) (Preece et al., 2017; Sifneos, 1973).

De PAQ (Preece et al., 2018) is een 24-item zelfrapportage meetinstrument voor alexithymie. Het is ontworpen om alle componenten van alexithymie te beoordelen, en doet dit over negatieve en positieve emoties. Vijf subschaal scores en zes samengestelde scores kunnen worden afgeleid van het meetinstrument, waarbij hogere scores duiden op hogere niveaus van alexithymie. Voor meer informatie over de ontwikkeling en psychometrische eigenschappen van de PAQ, zie Preece et al. (2018, 2020a, 2020b, 2020c) en Greene et al. (2020).

De tabel hieronder beschrijft de subschaal- en samengestelde scores van de PAQ en hoe ze berekend moeten worden. We hebben ook een Excel 'auto-scorer' spreadsheet gemaakt die helpt bij het scoren van de PAQ. Een kopie van de Excel auto-scorer kan hier worden gedownload:

https://www.researchgate.net/publication/329058432. Deze Excel-spreadsheet bevat ook enkele normatieve gegevens om te helpen bij de interpretatie van de PAQscores. Ons plan is om deze Excel auto-scorer te blijven bijwerken als er nieuwe normatieve gegevens beschikbaar worden.

\begin{tabular}{|c|c|c|}
\hline \multicolumn{2}{|r|}{ Hoe berekenen? } & \multirow{2}{*}{$\begin{array}{l}\text { Gemeten inhoud } \\
\text { oschaal scores }\end{array}$} \\
\hline \multicolumn{2}{|c|}{ Subschaal scores } & \\
\hline $\begin{array}{l}\text { Negatief-moeilijkheden om gevoelens te } \\
\text { identificeren (N-DIF) }\end{array}$ & Som items 2, 8, 14, 20 & Moeite om de eigen negatieve gevoelens te herkennen, te begrijpen en te onderscheiden. \\
\hline $\begin{array}{l}\text { Positief-moeilijkheden om gevoelens te } \\
\text { identificeren (P-DIF) }\end{array}$ & Som items 5, 11, 17, 23 & Moeite om de eigen positieve gevoelens te herkennen, te begrijpen en te onderscheiden. \\
\hline $\begin{array}{l}\text { Negatief-moeilijkheden bij het beschrijven van } \\
\text { gevoelens (N-DDF) }\end{array}$ & Som items 1, 7, 13, 19 & Moeite om de eigen negatieve gevoelens te beschrijven en te communiceren. \\
\hline $\begin{array}{l}\text { Positief-moeilijkheden bij het beschrijven van } \\
\text { gevoelens (P-DDF) }\end{array}$ & Som items 4, 10, 16, 22 & Moeite om de eigen positieve gevoelens te beschrijven en te communiceren. \\
\hline Algemeen-extern georiënteerd denken (G-EOT) & Som items $3,6,9,12,15,18,21,24$ & Neiging om de aandacht niet op de eigen emoties te richten (negatieve en positieve). \\
\hline \multicolumn{3}{|c|}{ Samengestelde scores } \\
\hline $\begin{array}{l}\text { Algemeen-moeilijkheden bij het identificeren } \\
\text { van gevoelens (G-DIF) }\end{array}$ & Som N-DIF and P-DIF subschalen & $\begin{array}{l}\text { Moeite om de eigen gevoelens (negatieve en positieve) te herkennen, te begrijpen en te } \\
\text { onderscheiden. }\end{array}$ \\
\hline $\begin{array}{l}\text { Algemeen-moeilijkheden bij het beschrijven } \\
\text { van gevoelens (G-DDF) }\end{array}$ & Som N-DDF and P-DDF subschalen & Moeite met het beschrijven en overbrengen van de eigen gevoelens (negatieve en positieve). \\
\hline $\begin{array}{l}\text { Negatieve-moeilijkheden bij het beoordelen } \\
\text { van gevoelens (N-DAF) }\end{array}$ & Som N-DIF and N-DDF subschalen & Moeite met het herkennen en beschrijven (d.w.z. beoordelen) van de eigen negatieve gevoelens \\
\hline
\end{tabular}


Positieve-moeilijkheden bij het beoordelen van gevoelens (P-DAF)

Algemeen-moeilijkheden bij het beoordelen van gevoelens (G-DAF)

Alexithymie (ALEXI; totale schaalscore)
Som P-DIF and P-DDF subschalen

Som N-DIF, P-DIF, N-DDF and P-DDF subschalen

Som alle items
Moeite met het herkennen en beschrijven ( $\mathrm{d} w \mathrm{z}$. beoordelen) van de eigen positieve gevoelens

Moeite met het herkennen en beschrijven ( $d$ w. $z$, beoordelen) van de eigen gevoelens (negatieve en positieve)

Algemene alexithymie; moeite met het richten van de aandacht op en het beoordelen van de eigen gevoelens (negatieve en positieve). 


\section{Beschrijvende statistieken van de PAQ}

Enkele beschrijvende statistieken en Cronbach's alpha-betrouwbaarheidscoëfficiënten van een Australische steekproef uit de algemene gemeenschap van volwassenen ( $N=748$; Preece et al., 2018) worden in de onderstaande tabel weergegeven.

\begin{tabular}{|c|c|c|c|c|c|c|c|}
\hline \multirow{2}{*}{$\begin{array}{l}\text { Subschaal/ } \\
\text { Samengestelde } \\
\text { scores }\end{array}$} & \multicolumn{3}{|c|}{ Gehele steekproef ( $N=748)$} & \multicolumn{2}{|c|}{ Vrouwen $(N=468)$} & \multicolumn{2}{|c|}{ Mannen $(N=280)$} \\
\hline & Gemiddelde & $S D$ & $\begin{array}{c}\text { Cronbach's } \\
\text { alpha }\end{array}$ & Gemiddelde & SD & Gemiddelde & SD \\
\hline \multicolumn{8}{|l|}{ Subschalen } \\
\hline N-DIF & 13.38 & 6.41 & 0.89 & 14.03 & 6.57 & 12.28 & 5.98 \\
\hline P-DIF & 11.30 & 5.76 & 0.89 & 11.38 & 6.08 & 11.18 & 5.20 \\
\hline $\mathrm{N}-\mathrm{DDF}$ & 15.35 & 6.89 & 0.91 & 15.80 & 7.00 & 14.60 & 6.63 \\
\hline P-DDF & 12.97 & 6.12 & 0.90 & 12.72 & 6.24 & 13.38 & 5.90 \\
\hline G-EOT & 28.97 & 11.19 & 0.90 & 27.92 & 11.35 & 30.74 & 10.72 \\
\hline \multicolumn{8}{|c|}{ Samengestelde scores } \\
\hline G-DIF & 23.68 & 11.28 & 0.92 & 25.41 & 11.57 & 23.45 & 10.68 \\
\hline G-DDF & 28.32 & 12.16 & 0.93 & 28.52 & 12.30 & 27.98 & 11.92 \\
\hline $\mathrm{N}-\mathrm{DAF}$ & 28.73 & 12.71 & 0.94 & 29.83 & 13.07 & 26.88 & 11.89 \\
\hline P-DAF & 24.27 & 11.39 & 0.94 & 24.1 & 11.95 & 24.55 & 10.41 \\
\hline G-DAF & 52.99 & 22.58 & 0.96 & 53.93 & 23.23 & 51.43 & 21.39 \\
\hline $\begin{array}{l}\text { ALEXI (totale } \\
\text { schaalscore) }\end{array}$ & 81.97 & 30.91 & 0.96 & 81.84 & 31.92 & 82.17 & 29.15 \\
\hline
\end{tabular}

\section{Score-interpretaties}

Om PAQ scores te interpreteren raden wij aan om de score van een respondent te vergelijken met scores van een geschikte normatieve steekproef. Alexithymie is een dimensioneel (in plaats van categorisch) construct dat normaal verdeeld is in de algemene bevolking, dus alexithymiescores kunnen het best worden gezien als bestaande op een continuüm. ledereen heeft een zekere mate van alexithymie, of dat nu een laag, gemiddeld of hoog niveau is. Het aantal standaarddeviaties (SD's) dat de score van een respondent afwijkt van het gemiddelde van een geschikte normatieve steekproef geeft de mate van alexithymie aan. We interpreteren PAQ-scores op de volgende manier, waarbij we in gedachten houden dat hogere scores duiden op een hoger niveau van alexithymie:

- Scores 1SD of meer boven het gemiddelde = "hoog niveau van alexithymie"

- Scores minder dan 1SD van het gemiddelde = "gemiddeld niveau van alexithymie"

- Scores 1SD of meer onder het gemiddelde = "laag niveau van alexithymie"

Deze Nederlandstalige vertaling van de PAQ is gemaakt door:

- Marta Walentynowicz (marta.walentynowicz@uclouvain.be)

- Elke Vlemincx (e.vlemincx@vu.nl)

- David Preece (david.preece@curtin.edu.au)

- Olivier Luminet (olivier.luminet@uclouvain.be) 


\section{References}

Greene, D., Hasking, P., Boyes, M., \& Preece, D. (2020). Measurement Invariance of Two Measures of Alexithymia in Students Who Do and Who Do Not Engage in Non-suicidal Self-Injury and Risky Drinking. Journal of Psychopathology and Behavioral Assessment, 1-18.

Preece, D., Becerra, R., Allan, A., Robinson, K., \& Dandy, J. (2017). Establishing the theoretical components of alexithymia via factor analysis: Introduction and validation of the attention-appraisal model of alexithymia. Personality and Individual Differences, 119, 341-352.

Preece, D., Becerra, R., Robinson, K., Dandy, J., \& Allan, A. (2018). The psychometric assessment of alexithymia: Development and validation of the Perth Alexithymia Questionnaire. Personality and Individual Differences, 132, 32-44.

Preece, D. A., Becerra, R., Boyes, M. E., Northcott, C., McGillivray, L., \& Hasking, P. A. (2020a). Do self-report measures of alexithymia measure alexithymia or general psychological distress? A factor analytic examination across five samples. Personality and Individual Differences, 155, 1-8.

Preece, D. A., Becerra, R., Allan, A., Robinson, K., Chen, W., Hasking, P., \& Gross, J. J. (2020b). Assessing alexithymia: Psychometric properties of the Perth Alexithymia Questionnaire and 20-item Toronto Alexithymia Scale in United States adults. Personality and Individual Differences, 166, 1-8.

Preece, D. A., Becerra, R., Robinson, K., Allan, A., Boyes, M., Chen, W., Hasking, P., \& Gross, J. J. (2020c). What is Alexithymia? Using Factor Analysis to Establish its Latent Structure and Relationship with Fantasizing and Emotional Reactivity. Journal of Personality, 1-15.

Sifneos, P. E. (1973). The prevalence of 'alexithymic' characteristics in psychosomatic patients. Psychotherapy and Psychosomatics, 22, 255-262. 